\title{
Education for Democratic Intercultural Citizenship (EDIC)
}

\author{
Wiel Veugelers
}

Why an EDIC+ Project? ${ }^{1}$

Europe and its participating countries need a strong democracy, an inclusive society, and active citizens. Intercultural and democratic competences are crucial for the future of Europe, its countries and its citizens. Education can play a central role in developing the necessary knowledge, skills and attitudes among young people.

Universities have a double role to play: they need to educate academics who can and want to contribute to such an inclusive and democratic society, and university-educated teachers, educational researchers and curriculum developers can work in schools and other educational institutions on empowering young people for active citizenship participation.

The pedagogical role of teachers in contributing to a more inclusive and democratic society is very important in this period of European history in which an increasing globalisation challenges traditional values. Strengthening international cooperation in all parts of Europe is very relevant to broadening the horizon of students, teachers, and academic researchers. A more inclusive and democratic society is as relevant for the future of Europe as economic growth. Education, and in particular teachers, can contribute to this moral enterprise. As research shows, attention for democratic and intercultural issues is currently not very strongly embedded in the curricula of teacher education and educational science.

\subsection{Why an Erasmus Strategy Partnership on EDIC?}

This strategic partnership aims to support democratic intercultural citizenship education in different ways, for instance by developing a joint curriculum and through the professional development of academic staff. The project will have a direct influence on students in the different modules and in intensive programmes. Strategic work will be done in own universities, through the cooperation between our universities, and with partners in civil society. The outcomes of this project will also be transferred to other universities and ultimately to

(C) KONINKLIJKE BRILL NV, LEIDEN, 2019 | DOI: 10.1163/9789004411944_001 
the society in each country. The project hopes to boost the social responsibility of universities and other institutes for higher education, and to contribute to active and engaged citizenship in Europe.

Through inter-university cooperation and the development of joint curricula, EDIC+ tries to contribute to a direct increase in social inclusion in partner countries and to the promotion of intercultural and civic competences among students. The quality and relevance of higher education will be improved, as the partner universities will have the opportunity to learn from each other's best practices and in this way to strengthen the field of Education for Democratic Intercultural Citizenship. The interdisciplinary nature of cooperation is addressed by including a broad range of partners representing social sciences, humanities, as well as teacher education.

By offering holistic Education for Democratic Intercultural Citizenship, the curricula developed during this project will support the future education of teachers and educational professionals, training them in how to promote European values, for example by preventing violent radicalisation, fostering social integration, and enhancing intercultural understanding (see Erasmus+ Guide 2016). The teaching/learning activities envisaged by this project (as well as educational activities continuing after the end of this project) will help participants build a sense of belonging to a European community. Further, the project seeks to develop social capital among future teachers and educational professionals, and to empower them to participate actively in European society by including a variety of international as well as local students and teachers.

The values of democracy and tolerance are currently strongly supported by the European Commission and the European Parliament. Education should play a central role in developing these values. (See European Commission, 2016: Promoting citizenship and the common values of freedom, tolerance and non-discrimination through education: overview of education policy developments in Europe following the Paris Declaration of 17 March 2015. Also see the Motion for a European Parliament resolution on the role of intercultural dialogue, cultural diversity).

\subsection{Education for Democratic Intercultural Citizenship}

Education prepares young people for the labour market, for living in society and for their personal well-being. For Europe and its countries it is very important that young people are prepared well for living and participating in a democratic and inclusive society. This preparation for society is called 'citizenship education'. Citizenship goals are formulated at the national, European and global level. Active or participatory citizenship of people, also young people, is considered to be crucial for the sustainability of future democracy in nation 
states and in Europe. Inclusiveness of different social and cultural groups and social and political integration at the national and European level is important for a peaceful future for all human beings, in Europe and worldwide.

Active and involved participation of citizens is not only the foundation for the well-being of society, but also for the spirit of entrepreneurship in our societies. Economic, social and cultural entrepreneurship and citizenship are interlinked and necessary for a sustainable, dynamic and future-oriented society. Cooperation, dialogue and intercultural communication between people and groups are a source of creativity and diversity, and can stimulate possibilities for many people to live a good life and to contribute to a humane and flourishing society. A strong educational focus on democratic and intercultural citizenship development in all areas of education is very relevant for the future of Europe and its citizens.

The objectives of the project are to develop an international curriculum at the university level that supports (future) teachers and educational scientists in creating curricula and practices for Education for Democratic Intercultural Citizenship (EDIC) at all levels of education to cultivate future European citizens. Until now, citizenship education, particularly with a focus on democracy and intercultural dialogue, has not received much attention in teacher education and educational studies (for review studies Veugelers, 2010; Bhatti \& Leeman, 2011; Tirri, 2011; Sanger \& Osguthorpe, 2013; Teodoro \& Guilherme, 2014).

University educational programmes, especially teacher training curricula, currently lack sufficient practice with regard to teaching topics related to democratic intercultural citizenship education. At the same time, developments in European society are adding urgency to the need for these competences among teachers and educational specialists. We think that a strong stimulus is needed in this area of education. Future Europe needs a democratic and inclusive society with critically engaged citizens, and education can contribute to this.

\section{$2 \quad$ Strategy of EDIC+}

The educational programme we will develop during the three project years will consist of different modules in different universities and joint intensive programmes for teachers and students. The programme will be research-oriented, comparative, and linked with civil society. Most importantly, the project will be transnational: universities from the south (Barcelona, Thessaloniki), the north (Helsinki and Tallinn), the west (Bath, Utrecht) and the east of Europe (Prague) are participating. The programme will express European inclusiveness, with 
attention for national, regional and local differences. The modules developed will give Master students the opportunity to make choices and to develop a personal profile within the field of democratic intercultural citizenship education. The programme will be open to all students. In particular, we want to include prospective teachers (of all school subjects), educational researchers and curriculum designers.

The intensive programmes will be international educational activities in themselves and the motor for the development of modules. In the intensive programmes, parts of the modules will be tried out and critically reflected on by peer-teachers and students from different universities and different parts of Europe.

The following seven modules have been agreed upon:

1. University of Humanistic Studies Theory and Practice of Citizenship Education

2. University of Barcelona Ethical Competencies for Democratic

Citizenship at School and in Families

3. University of Bath Spa Social and Educational Inclusion in Schools and their Communities

4. University of Helsinki Teachers' Moral Competence in Pedagogical Encounters

5. Charles University Prague Educational Activities in Civil Society

6. University of Tallinn Education Policy and Citizenship in Education

7. Aristotle University Thessaloniki Multicultural/Intercultural Education

In choosing these seven topics, we are drawing on the expertise of the different universities and have compiled a relevant combination of topics that together cover the broad area of Education for Democratic Intercultural Citizenship.

\subsection{Objectives of EDIC +}

The concrete objectives of the project are:

1. To develop a curriculum for Education for Democratic Intercultural Citizenship (EDIC), formally recognised and supported by seven universities in different parts of Europe.

2. To stimulate student exchange in this area and gather collective experiences in intensive programmes. 
3. To promote the professional development of teachers in this field (and a professional development programme).

4. To stimulate a more complex, critical and engaged concept of citizenship that combines social, political, intercultural and entrepreneurial components.

5. To strengthen the cooperation between universities and civil society.

6. To develop a partnership between European universities that stimulates cooperation between researchers, teachers and students in this field.

7. To develop curriculum materials and student products with open access and on the EDIC website.

8. To educate a new generation of teachers, curriculum developers, and researchers.

In an intensive cooperation, the group of experts of the seven universities will develop a European curriculum, in which the national level, the European level, and the global level are included. The curriculum will be research-oriented, will use the experiences and expertise of the participating countries in a comparative way, will link the universities with civil society institutions, and will create possibilities for Master students to gain international experiences.

The project aims to educate a new generation of teachers, educational scholars and practitioners who are oriented towards the needs of a future global world, and Europe in particular. It will lead to the inclusion of more dynamic, intercultural, comparative and research-oriented learning in the curriculum of universities.

\subsection{From EDIC to EDIC+}

Most universities involved in this project participated with their students and teachers in the highly successful Erasmus Intensive Programmes in May 2013 in Utrecht and May 2014 in Barcelona. These universities see the development of a common curriculum as the next complementary step. The intensive programmes demonstrated the specific expertise of the participating universities and teachers, stimulated the connection of different theories, and shared interesting teaching methods. In this way, the programmes have contributed to closer cooperation between the involved universities in teaching and research.

This Erasmus Strategic Partnership gives the opportunity to build a platform, a network, a curriculum and experts in the field of Education for Democratic Intercultural Citizenship. It takes the cooperation between the involved universities to a higher level. The new EDIC+ project can advance curriculum development, teachers' expertise, and student exchange. On the inter-institutional level, there will be a joint curriculum and an organisational 
structure that can support the project, stimulate knowledge transfer to other universities, and develop new initiatives in the field of citizenship and intercultural education.

\subsection{Task of Participating Universities}

Each partner is responsible for the development and teaching of one module. Further, each partner will have an EDIC coordinator and one assistant coordinator, although more teachers and researchers will be involved in the local team. Both the coordinator and assistant coordinator will have a teaching task in the module. Each partner also has to stimulate student exchange and contribute to the joint activities such as the intensive programme, and on the curriculum level to ensure a fit between the modules and the formal procedures to develop a joint certificate. Each partner communicates regularly with their cooperating civil society organisations. Once a year, they will each have a meeting with all these civil organisations to exchange experiences and develop new initiatives.

Each year in autumn there is a transnational project meeting of the EDIC + coordinators of the seven universities. Herein, management policy, finance, and coordination of the curriculum development and the supporting research activities will be addressed.

Each year in spring there will be an intensive transnational programme of 10 days. Students and teachers of the involved universities will participate in this intensive programme. The programme will hold educational value for the students and professional development potential for teachers. During this programme, curriculum development will be assessed, research and design activities will be coordinated, and the exchange of students will be monitored.

To stimulate further cooperation between the universities, the module developed at each university will also host a visiting professor from one of the other partners. This scholar will give a lecture and workshop in the module and will inquire into the theory and practice of the module as a 'critical friend'.

\subsection{Outcomes of the Project}

These 12 results are envisioned over a period of three years (September 2016August 2019):

1. The joint development of a curriculum for Education for Democratic Intercultural Citizenship (EDIC+), a network structure, and an intensive programme.

2. The development of one 7.5 ECTS (Master level) module (in English) by each participating university. The seven modules will together constitute 
the integrated curriculum EDIC+. All materials will be published (in an open-access book and on the EDIC+ website).

3. The recognition of all seven modules by all EDIC universities. All universities will offer the entire EDIC+ curriculum to their students.

4. Signing of an agreement by all EDIC universities for student exchange with other participating universities through Erasmus grants.

5. Participation of students from these seven universities and students from other universities in these modules. Students can use Erasmus exchange grants for participating in modules at other universities.

6. Awarding of an EDIC + certificate to students after completing two or more modules of the EDIC curriculum. (For students of the EDIC universities this can be a module at their own institute and a module at one of the other universities. The intensive programme can be part of one of the modules).

7. All modules will have the following methodological elements:

a. Combination of theory and practice

b. Link with civil society institutions (site visits, guest lectures)

c. Research and change orientation

d. International and comparative orientation through the use of data and examples from other countries, in particular the EDIC+ participants

e. A visiting professor in each module from one of the other EDIC universities to give a lecture and act as a critical friend during the process of curriculum development.

8. Creation of a team of scholars who can function as experts, co-supervisors or members of a Master or PhD-tribunal in the other participating universities.

9. An academic international e-journal offering students the opportunity to publish their research, their curriculum material and their educational experiences. (We had to drop this goal because an Erasmus Strategic Partnership cannot finance such an activity.)

10. An annual intensive programme (IP) of ten days for students and teachers. After the project period, other resources, such as Erasmus exchange grants, will be used to continue with the IP.

11. Dissemination of activities in all participating countries; at the European level presentations will be given at leading educational conferences (ECER, EARLI, ATEE).

12. Setting-up of a proper management structure to ensure the sustainability of the EDIC+ curriculum after the EDIC+ project is completed. 


\subsection{Developmental Process}

1. First year: develop an outline for own module, carry out comparative research, and teach a number of essential components of the modules at own university.

2. Second year: first try-out of prototype modules.

3. Third year: second try-out of modules, with focus on assessment and sustainability/implementation.

4. Each year: an intensive programme of ten days with the following components:

a. A try-out of elements of the modules

b. Gathering ideas and feedback of the students to improve the modules (students as co-constructors of the modules). From each university, two teachers and three students can participate.

5. Each year: three-day management and curriculum meeting of the coordinators of each university to work on the curriculum development, in particular on connections between the modules, to guide comparative research activities, to monitor the quality of modules, and to arrange institutional conditions (recognition of modules, exchange contracts between the universities). Also, the organisation and financial situation will be evaluated and monitored.

6. Set up internet platform: internal (in first year) for participating teachers and students, and external (with open access) (by third year) for other interested scholars, students, policy-makers, etc.

7. Prepare and publish (open access) book and curriculum material.

Students of (teacher) education programmes in the participating universities and other universities will be the main beneficiaries of this project. The target group consists of future teachers and other educationalists, curriculum developers, and academic researchers. The purpose is to educate a new generation of engaged, competent and entrepreneurial educators involved in making society more democratic, intercultural, inclusive and future-oriented (in Europe and in a global world).

By developing this programme we aim to contribute to creating university curricula that are research-oriented, comparative, civic-embedded, and society-linked. Because of their multidisciplinary approach and focus on active and dialogic learning, the developed curricula can serve as an example for future curriculum development in (other) universities.

Both own students at the respective universities and exchange students can benefit from the developed modules. They will participate in a module that is international, research-based, and linked to society. The idea is that the curriculum stimulates connections with civil society, and a critical engagement 
with democracy and with the role education can play in building a more inclusive society.

The specific tasks leading to the production of the intellectual output are as follows:

- Analysing possible target groups who would be interested in participating in this module.

- Defining the aims of the module according to the goals of EDIC+ and the needs of the target groups.

- Collecting data from other EDIC+ countries through comparative research.

- Describing the content of the module according to its aim, and analysing and incorporating new changes brought on by field experience and the results of latest research findings.

- Making agreements with civil society organisations and schools for guest lectures and field visits.

- Describing the learning outcomes and assessment criteria.

- Piloting parts of the module in the EDIC+ intensive programmes and at own universities.

- Discussing the programme and its practice with the visiting EDIC+ teacher.

- Improving the module.

- Producing a final version of the module.

\subsection{Developmental Process}

The strategic partnership gave the opportunity to intensify the cooperation between the seven European universities. The project started in September 2016 and ended on August 31 2019. We are writing this result paragraph already in January 2019, so not all developments in the third project year can be included. However, we wish to have this results paragraph in the book that will be presented at the final international multiplier event held in Utrecht on 19-20 June.

The Intensive Programmes could be continued and now serve as a motor for the curriculum development in each university, an international learning site for students, a professional development environment for teachers, and a platform for new initiatives. During each Intensive Programme, there was always a meeting of all teachers on the curriculum development in which we discussed the progress of the modules.

The module development in each university focused on the embedding of EDIC+ elements in the curriculum of the participating universities and on the 
development of a specific module for the joint inter-university EDIC + curriculum grounded on the own expertise. All the universities could organise tryouts of the modules or at least crucial and new elements of it.

Critical friends attended another university, gave a lecture in the EDIC+ module and reflected on the curriculum development. The critical friend was in the second and third year a powerful instrument to collaborate at the teaching level itself. Both the critical friend and the receiving university were positive about it.

Meetings of the executive committee were held during the Intensive Programmes and one in the autumn of each year. At this meeting, the organisation of the whole project, the organisation in the different universities, the progress of the deliveries, implementation and dissemination, and new initiatives were discussed. We could attend as executive committee of EDIC+ all participating universities. This was also very helpful to understand the specific expertise and context of each university and to support the implementation of EDIC+ in the university by meeting relevant officials of the university.

\subsubsection{Link with Teaching Common Values Research}

At the same time that the Erasmus Strategic Partnership EDIC+ started, the European Parliament asked us to perform a comparative research on the policy and practice of teaching the common values democracy and tolerance in all 28-EU Member States (Veugelers, De Groot, \& Stolk, 2017). In all 28 EU Member States, academic experts collected data on the policy and practice of teaching democracy and tolerance. Additional data were collected through case studies in 12 countries. These 12 countries included the seven countries involved in EDIC+. This research was a great stimulus for getting data, doing comparative research and building a network of academic experts on citizenship education in all EU Member States.

\subsection{Intensive Programmes}

The 10-day Intensive Programmes (IP) are always held in spring. In 2017 the IP was in Prague, in 2018 in Tallinn and Helsinki, and in 2019 in Thessaloniki. Three students of each university participated. At all the universities, there were more students with an interest in the programme. In 2018 there were two students who rejoined the IP, now covering their own costs directly.

One interesting aspect was the participation of several students from outside Europe (Iran, China, Columbia, Chile, Venezuela, Ghana). Their experiences with intercultural citizenship and education expanded the view and made the programme more global. 
In each IP, all the teachers presented parts of their module in a lecture or workshop. Students also had the opportunity to talk with them more informally in round table sessions. School visits were made that allowed students to observe lessons and to talk with principals, teachers and pupils. Guest lectures were given by representatives of NGOS, and guided tours were made in the city with a focus on citizenship (you can read more about the IPs in Chapter 9).

The students always stayed for the full 10 days; teachers between 4 and 6 days. The schedules of the teachers were arranged around the curriculum meeting and the meeting of the executive committee. Teachers were responsible for the selection, guiding and assessment of the students of their university. Students could actively participate in the programme by presenting their research, their analyses of Education for Democratic Intercultural Citizenship in their country, through dialogues with teachers and other students, and through the many joint formal and informal meetings during their stay (Students' experiences in the IPs are presented in Chapter 10).

\subsection{Module Development}

In the first year, all the universities made a first draft of their module. The topic was chosen with a view to the expertise of the university and their participating staff. The drafts were discussed in the curriculum meeting during the IP in Prague. In the second year each university planned a try-out of the module (or central parts of it).

The organisational embedding of the module was quite a challenge. Two models emerged: modules that take a long time, 8-10 weeks with weekly activities (Tallinn; Thessaloniki) or intensive modules of one or two weeks (Helsinki, Utrecht, Bath). Some modules also had an in-between structure (Barcelona, Prague). In the first year Barcelona and Prague could only organise try-outs of small parts of the module because they could not find enough students to participate.

All the universities could develop their module within the theoretical topic they had chosen. Connections with schools and civil society were made. Students also had the opportunity to get actively engaged in the programme. As said before, the critical friends in the module were really an addition to the content of the module and to the dialogues about the programme.

The experiences with the modules, the reflection on these experiences and the renewed plans were discussed in the curriculum meeting during the IP in Tallinn. In that meeting, a first draft of the chapters of the book was discussed. A second draft was discussed in the executive committee in autumn 2018 in Barcelona. 


\subsection{Teacher and Student Participation and Exchanges}

Much has been said about the participation of teachers and students in the Intensive Programmes. This was close to perfect. All participants see the value of the Intensive Programme in itself and as a motor of the curriculum development and the professional development of the teachers. We hope we can continue these Intensive Programmes!

The critical friendship element was also perceived as positive; unfortunately, three visits could not be arranged in the first year. For the third year all friendship visits could be arranged. Some arrangements to continue these visits in the future have already been made, for example by using Erasmus teacher exchange grants.

Getting Master students to participate in the modules at the different universities was not so easy. We do not yet have all the data for the third year, but can already make the following two comments:

- EDIC+ focuses on Master and PhD students. Most of their programmes are very structured and do not leave not much room for flexibility and choices. Most universities became more aware of this bonding of students to their own programme and are searching for more choices and flexibility in Master and PhD-programmes.

- Erasmus exchange grants for students require a period of at least three months. For Master and $\mathrm{PhD}$ students, this period is often too long (see first point). Having grants for say two weeks would strongly facilitate student exchange and participation in full-time programmes.

Nevertheless, nearly all modules had enough students to run the programme, either because they actually had a group of $15^{-20}$ students (Helsinki; Thessaloniki), or a small group of eight students (first year Utrecht) in which four Dutch and four exchange students worked intensively together; or because the module was included in a regular course with interested foreign students attending (Tallinn).

\subsection{Implementation and Dissemination}

All seven universities continue their curriculum work and try to include the EDIC+ module and crucial elements in their regular programme. Working on the EDIC+ modules has stimulated a stronger focus on society, international developments and on the role of intellectuals in it. Democracy and intercultural developments are getting more attention at the involved universities.

Students that participated in the Intensive Programmes still have many contacts with each other and are really EDIC ambassadors. In each country a national multiplier event has been organised in May in which colleagues of other universities, policy-makers and NGOs learn about the outcomes of 
EDIC+. This book will be presented at the final international multiplier event June 2019 .

\section{Note}

1 Parts 1 and 2 of this chapter are strongly based on the submitted proposal.

\section{References}

Bhatti, G., \& Leeman, Y. (2011). Convening a network within the European conference on educational research: A history of the social justice and intercultural education network. European Educational Research Journal, 10(1). 129-142.

Sanger, M., \& Osguthorpe, R. (Eds.). (2013). The moral work of teaching and teacher education. New York, NY: Columbia University.

Teodore, A., \& Guilherme, M. (2014). European and Latin America Higher Education between mirrors. Rotterdam, The Netherlands: Sense Publishers.

Tirri, K. (2011). Holistic school pedagogy and values: Finnish teachers' and students' perspectives. International Journal of Educational Research, 50, 159-165.

Veugelers, W. (2010). Moral values in teacher education. International Encyclopedia of Education, $7,650-655$.

Veugelers, W., De Groot, I., \& Stolk, V. (2017). Research for Cult Committee - Teaching common values in Europe. Brussels: European Parliament, Policy Department for Structural and Cohesion Policy. Retrieved from http://bit.ly/2pm5Yh9 